\title{
$\widehat{A}$ Madridge \\ madridge Journal of Dentistry and Oral Surgery \\ interconnectin
}

Letter to Editor Article

Open Access

\section{Oral Health \& Chronic Disease Integration: The Call fora New Public Health Systems Approach for Dental Research}

\author{
Amy Brock Martin ${ }^{1 \star}$ and Marcia Brand ${ }^{2}$ \\ ${ }^{1}$ James B. Edwards College of Dental Medicine, Medical University of South Carolina, Basic Sciences Building, Room 127, 173 Ashley \\ Avenue, Charleston, SC 29425, USA \\ ${ }^{2}$ Senior Advisor for National Policy and Programs, DentaQuest Foundation Executive Director, National Interprofessionalism
} Initiative in Oral Health, USA

\section{Article Info}

*Corresponding authors:
1. Amy Brock Martin
Director and Associate Professor
Division of Population Oral Health
James B. Edwards College of Dental Medicine
Medical University of South Carolina
Basic Sciences Building, Room 127
173 Ashley Avenue
Charleston, SC 29425, USA
Tel: 843-792-8270
E-mail: martinamy@musc.edu

E-mail:martinamy@muscedu

\section{Marcia Brand}

Senior Advisor for National Policy and Programs DentaQuest Foundation

Executive Director

National Interprofessional Initiative in Oral Health

Received: June 24, 2016

Accepted: July 27, 2016

Published: October 9, 2016

Citation: Martin AB, Brand M. Oral Health Chronic Disease Integration: The Call for a New Public Health Systems Approach for Dental Research. Madridge J Dent Oral Surg. 2016; 1(1): 21-22.

doi: $10.18689 / \mathrm{mjdl}-1000105$

Copyright: @ 02016 The Author(s). This work is licensed under a Creative Commons Attribution 4.0 International License, which permits unrestricted use, distribution, and reproduction in any medium, provided the original work is properly cited.

Published by Madridge Publishers

\section{To the Editor:}

The Institute of Medicine (IOM) has documented both the role oral health plays in total wellness and the challenges around access to oral health care faced by underserved populations and those with chronic diseases like diabetes. IOM publications recommend an improvement agenda that emphasizes integrated oral health and medical care models and policies [4]. What does it mean to integrate, as a part of public health transformation? One definition, offered by chronic disease specialists: "the strategic alignment of chronic disease categorical program resources to increase the effectiveness and efficiency of each program in a partnership without compromising the integrity of categorical program objectives [5]."

While oral health and chronic disease $(\mathrm{OH}-\mathrm{CD})$ integration is not explicitly addressed in the Affordable Care Act (ACA), there are a number of provisions that support its implementation in both policy and practice. Five ACA provisions regarding oral health could provide opportunities for $\mathrm{OH}-\mathrm{CD}$ integration [6]. They include:

- CDC-led national oral health care prevention education campaign;

- Dental training program grants;

- Oral health inter professionalism workforce demonstration grants for non-dental providers;

- Community health center oral health awards; and

- National Health Care Workforce Commission, which has identified oral health as a priority area.

In parallel, three chronic disease provisions in Title IV, "Prevention of Chronic Disease and Improving Public Health," of the ACA directly align with $\mathrm{OH}-\mathrm{CD}$ integration [7].

Prevention and obesity-related services create opportunities to integrate oral health promotion and disease prevention messages. The obvious linkage is nutrition and the impact it has on oral health and weight, particularly among America's children. Healthy school options provided public schools are often not made available in communities at highest risk for obesity or unmet dental need [8]. And if made available, many children continue to opt for meals with thin nutritional benefit [9]. More systemic, clinical implications include co-occurring diabetes and periodontal infection, as an example, The second provision is related to tobacco use during pregnancy. The intersection of tobacco use and pregnancy could include oral cancer and preterm labor prevention, "in addition to" how to integrate oral health promotion in the prenatal care experience, as it is related to tobacco control. Finally, Section 4108 of ACA established the Medicaid Incentives for Prevention of Chronic Diseases Program. If states strategically integrate $\mathrm{OH}-\mathrm{CD}$, they have the dual benefit of improving health status and medical savings as well as dental savings. 
Both the oral health and chronic disease ACA provisions are in alignment with the CDC Division of Oral Health's Strategic Plan for 2011-2014, especially Objective 2, "Guide Dental Public Health to be Part of the Health System Transformation [10]." We have seen an important funding opportunity come from CDC as a part of this effort, "Models of Collaboration for State Chronic Disease and Oral Health Programs," (CDC-RFADP16-1609). Additionally, the U.S. Department of Health and Human Services released its Oral Health Strategic Framework in 2016 with its first of five goals focused on integrating oral health into primary care [11].

Foundations and other philanthropic policy partners also recognize the value of oral health integration into primary care. Grant makers in Health $(\mathrm{GIH})$ published an issue brief in 2012 that addressed oral health and primary care integration [12]. In this issue brief, GIH members explore areas of potential grant maker investments, including model development and testing; workforce development; stakeholder education; and oral health finance reform.

In summary, contemporary health reform policies, as well as strategic plans and grants of both federal and philanthropic organizations, suggest a diverse portfolio of $\mathrm{OH}-\mathrm{CD}$ integration activities that is occurring at national, state, and communitylevels. Understanding how these activities and policies impact the epidemiology of both oral health and chronic diseases are essential as public policy continues to move towards integrated care models, value-based purchasing of healthcare services, and shared risk-shared reward reimbursement that bundles dental care into accountable care organization models.

Framing evaluation research of $\mathrm{OH}-\mathrm{CD}$ integration in a public health context should be organized along two dimensions: prevention and integration. The Spectrum of Prevention, originally developed at the Contra Costa Health Services Prevention Program, provides a logical organization for interventional research [13].

The Spectrum delineates six levels of strategy development for comprehensive prevention, in our case $\mathrm{OH}-\mathrm{CD}$ integration (Figure 1) [13].

\begin{tabular}{|c|}
\hline Figure1. Spectrum of Prevention \\
\hline \\
\hline Influencing policy \& legislation \\
\hline Changing organizational practices \\
\hline Fostering coalitions \& networks \\
\hline Educating providers \\
\hline Promoting community education \\
\hline Strengthening individual knowledge \& skill \\
\hline
\end{tabular}

Each of the Spectrum's levels is intended to complement the others for optimal impact. Its creator demonstrated its usefulness in framing prevention as a vehicle for health equity [14]. Designing the intervention research approaches with this framework in mind allows information to be better understood relative to its role in advancing comprehensive prevention through $\mathrm{OH}-\mathrm{CD}$ integration.

Understanding integration configurations is also essential in assessing intervention effectiveness. IOM describes integration as a continuum. Scaling upwards from silos (least integrated) to full integration, $\mathrm{OH}-\mathrm{CD}$ integration could be described as mutual awareness (e.g. two public health divisions are aware of each other's work), collaborations (e.g. oral health coalitions), single discipline inter professionalism (e.g. primary care oral health services) and co-location of services (e.g. FQHCs with dental programs) [15]. Describing OH-CD integration efforts along the two dimensions of prevention and integration configuration will provide a more in depth synthesis of how activities are organized and responsive to public health and health services policies.

Application of these types of frameworks will become more prevalent in peer reviewed dental research as patient compositions change radically in the United States. Dental visits in community health centers increased nearly $74 \%$ between 2006 and 2012 where chronic disease management models are employed to achieve population health indicators imposed by their funders and CMS.

\section{References}

1. Institute of Medicine. Advancing Oral Health in America. Washington, DC: The National Academies Press. 2011.

2. Hostetter M, Klein S. In Focus: Integrating Oral Health into Primary Care. Quality Matters. The Commonwealth Fund. 2015.

3. AAFP. American Academy of Family Physicians. 2015.

4. Institute of Medicine. Improving access to oral health care for vulnerable and underserved populations. Washington, DC: The National Academies Press. 2011.

5. Salinsky E, Gursky EA. The case for transforming governmental public health. Health Affairs. 2006; 25(4): 1017-1028. doi: 10.1377/hlthaff.25.4.1017

6. The Network for Public Health Law. Improving Oral Health Care: ACA Initiatives and IOM Recommendations. 2012.

7. U.S Department of Health and Human Services. Prevention of Chronic Disease.

8. Franco M, Diez-Roux AV, Nettleton JA, et al. Availability of Healthy Foods and Dietary patterns: the Multi-Ethnic Study of Atherosclerosis. Am J Clin Nutr. 2009; 89(3): 897-904. doi: 10.3945/ajcn.2008.26434

9. Gross SM, Zucker A, Biehl E, et al. Does selection of foods in the school cafeteria by 6-8 year olds translate into consumption? Results of a cafeteria observation study. The American Public Health Association's Annual Meeting. 2014.

10. Centers for Disease Control and Prevention. Division of Oral Health Strategic Planning for 2011-2014. CDC.

11. Nicholas S. Makrides. U.S. Department of Health and Human Services. Oral Health Strategic Framework, 2014-2017. Public Health Rep. 2016; 131(2): 242-257.

12. Grant makers in Health. Returning the Mouth to the Body: Integrating Oral Health and Primary Care. Issue Brief Grant makers Health. 2012; (40): $1-31$.

13. Cohen L, Swift S. The prevention institute. The spectrum of prevention: developing a comprehensive approach to injury prevention. Inj Prev. 1999; 5(3): 203-207. doi: 10.1136/ip.5.3.203

14. Chehimi S, Cohen L, Valdovinos E. In the first place: Community prevention's promise to advance health and equity. Environment and Urbanization. 2011; 23(1): 71-89. doi: 10.1177/0956247811398600

15. No authors. Primary care and public health: Exploring integration to improve population health. Institute of Medicine. Washington (DC): National Academies Press (US). 2012. 